\title{
Mechanistic modeling of polysulfide shuttle and capacity loss in lithium-sulfur batteries
}

\author{
Andreas F. Hofmann ${ }^{\mathrm{a}, \mathrm{b}, *}$, David N. Fronczek ${ }^{\mathrm{a}, \mathrm{b}}$, Wolfgang G. Bessler ${ }^{\mathrm{c}}$ \\ ${ }^{a}$ German Aerospace Center (DLR), Institute of Technical Thermodynamics, Pfaffenwaldring 38-40, 70579 Stuttgart, Germany \\ ${ }^{b}$ Helmholtz Institute Ulm (HIU) Electrochemical Energy Storage, 89081 Ulm, Germany \\ ${ }^{c}$ Institute of Energy System Technology (INES), Offenburg University of Applied Sciences, Badstrasse 24, 77652 Offenburg, Germany
}

\begin{abstract}
Lithium-sulfur (Li/S) cells are promising candidates for a next generation of safe and cost-effective high energy density batteries for mobile and stationary applications. At present, most Li/S cells still suffer from relatively poor cyclability, capacity loss under moderate current densities and self-discharge. Furthermore, the underlying chemical mechanisms of the general discharge/charge behavior as well as Li/S-specific phenomena like the polysulfide shuttle are not yet fully understood. Here we present a thermodynamically consistent, fully reversible continuum model of a $\mathrm{Li} / \mathrm{S}$ cell with simplified four-step electrochemistry, including a simple description of the polysulfide shuttle effect. The model is parameterized using experimental discharge curves obtained from literature and reproduces behavior at various current densities with fairly high accuracy. While being instructively simple, the presented model can still reproduce distinct macroscopic Li/S-cell features caused by the shuttle effect, e.g., seemingly infinite charging at low charge current densities, and suboptimal coulombic efficiency. The irreversible transport of active material from the cathode to the anode results in a voltage drop and capacity loss during cycling, which can also be observed experimentally.
\end{abstract}

Keywords: lithium sulfur battery, modeling, simulation, polysulfide shuttle effect, cyclability, coulombic efficiency

\section{Introduction}

It is commonly agreed on that conventional lithiumion batteries, which have been commercialized since the early 1990ies, have intrinsical energy density limits due to their intercalation-type chemistry [1, 2,3,4]. The lithium sulfur $(\mathrm{Li} / \mathrm{S})$ system emerges as a promising candidate for next generation lithium-based batteries $[5,6]$. Due to the high theoretical specific capacity of sulfur of $1675 \mathrm{Ah} \mathrm{kg}^{-1}$ and the associated high energy density of $2600 \mathrm{Wh} \mathrm{kg}^{-1}[7,4]$, a practical Li/S battery system should allow for approximately twice the gravimetric energy density $\left(\approx 500 \mathrm{Wh} \mathrm{kg}^{-1}\right)$ of conventional lithium ion systems $\left(200-250 \mathrm{Wh} \mathrm{kg}^{-1}\right)$ [7]. Also, $\mathrm{Li} / \mathrm{S}$ batteries promise a high cost-effectiveness due to the broad availability of sulfur and the associated low production costs [1].

While lithium-sulfur research has been going on for about four decades $[8,9,10,11,12,13], \mathrm{Li} / \mathrm{S}$ battery systems have not been commercialized in a wide-spread

${ }^{*}$ Corresponding author. E-mail address: andreas.hofmann@ @lr.de fashion yet, mainly due to the remaining problems of low cyclability, uncompetitive practical specific energy at the current state of the technology (200-300 Wh $\mathrm{kg}^{1}$ ), and non-negligible self-discharge propensities $[1,14]$. Most of these problems are associated with the specific electrochemical characteristics of the lithium-sulfur system: while the fully oxidized (elemental sulfur, $\mathrm{S}_{8}$ ) and the fully reduced (lithium sulfide, $\mathrm{Li}_{2} \mathrm{~S}$ ) end-products are crystalline or amorphous solids $[15,16]$, the dominant species during discharge and charge of $\mathrm{Li} / \mathrm{S}$ batteries are (lithium) polysulfides, which are soluble in ether-based electrolytes such as tetra-ethylene-glycol-dimethyl-ether (TEGDME), commonly used for Li/S battery systems [7]. The involved multi-step reduction and oxidation reactions of dissolved polysulfides, as well as the phase-change behavior due to dissolution and precipitation of elemental sulfur and lithium sulfide, involve complex (electro)chemistry and are thus far poorly understood (see $[17,18,7]$ for proposed mechanisms). Increased fundamental understanding of the electrochemistry of the $\mathrm{Li} / \mathrm{S}$ battery system is therefore a requirement to bring $\mathrm{Li} / \mathrm{S}$ technology closer to wide-spread commer- 
cialization and public availability.

While there are some insightful experimental studies investigating the general electrochemical properties and the discharge/charge behavior of $\mathrm{Li} / \mathrm{S}$ cells $[19,14,20,21,7,16,22,4]$, as well as the microstructure and structural change of electrodes and electrolytes for $\mathrm{Li} / \mathrm{S}$ systems [23, 24, 25, 26, 27, 28, 29, 15, 30], the literature on mathematical models of $\mathrm{Li} / \mathrm{S}$ batteries is surprisingly sparse. Kumaresan et al. [31] presented a detailed multi-step model employing Butler-Volmer kinetics. The model was applied only to a discharge at a $\mathrm{C} / 50$ rate and was not quantitatively validated against experimental data. Fronczek and Bessler [32] used a similar mechanism to study extended operating ranges, including the prediction of electrochemical impedance spectra, however, still without experimental validation.

A particular challenge is the complex multi-step chemical mechanism. Due to the lack of knowledge of thermodynamical properties of dissolved lithium-polysulfide intermediates, a fully detailed model resolving all possible redox steps will inevitably feature many calibrated (assumed) parameters and its electrochemical interpretation is therefore of limited value. Still, the models presented to date allowed to identify key processes responsible for the electrochemical characteristics of $\mathrm{Li} / \mathrm{S}$ cells. In this article, we present a simplified, fully reversible Li/S-battery model that is for the first time validated against experimental discharge curves obtained from Cheon et al. [5].

In our model, the chemistry of the intermediate, dissolved polysulfides is deliberately represented in a simplified fashion employing three dissolved intermediates and two reduction steps. With the simplified model presented here, the parameter space to be calibrated is reduced, which keeps the model numerically and computationally manageable, and key Li/S-cell properties can be more easily interpreted. The model is used to investigate charge and dischare at different rates, the polysulfide shuttle, as well as cyclability and capacity loss.

It is well known that in liquid-electrolyte $\mathrm{Li} / \mathrm{S}$ cells, the mobility of the soluble polysulfide intermediates in the electrolyte can create a "shuttle" effect, especially during charging $[5,12,33,34,35]$. This phenomenon occurs during charging if polysulfides are reduced at the negative electrode, where electrons are readily available. The shorter polysulfides migrate back to the positive electrode where they are oxidized again. The current associated with these reactions does not contribute to charging the electrodes, causing a low coulombic efficiency. In addition, this effect contributes to commonly observed shortcomings of liquid-electrolyte Li/S cells like poor cyclability and high self-discharge rates. The shuttle effect is most prominent at low, constant charging current densities, where it can lead to seemingly "infinite" charging with the voltage reaching a plateau phase below the constant current charge cutoff voltage. The models presented by Kumaresan et al. [31] and Fronczek and Bessler [32] do not include this shuttle mechanism. A phenomenological model of the polysulfide shuttle is discussed in [35]. However, this model does not explicitly describe the shuttle in terms of charge transfer reactions and transport of the polysulfides. Instead, one global parameter (the shuttle constant $k_{S}$ ) is introduced, which is effectively a measure of the fraction of the current going into the shuttle effect. While this approach works well for [35], a study that focusses on the heat generation during charging and only shows a small set of simulation results relevant to this issue, it does not describe the shuttle effect in sufficient detail for our purposes. In addition to an explicit treatment of the shuttle mechanism, our model includes the possibility of precipitation of lithium-sufide on the anode side, with a respective feedback on the anode active surface. This allows for a simulation of cell degradation due to cycling, which qualitatively follows experimental results from literature and thus provides valuable insights into the key mechanisms leading to shortcomings in current state-of-the-art liquid electrolyte Li/S cells.

\section{Methodology}

\subsection{Model layout and implementation}

The model presented here uses the same basic layout and 1-D transport as presented in Fronczek and Bessler [32]. The model is implemented in the modeling framework DENIS (detailed electrochemistry and numerical impedance simulation) [36], which can be used for simulations of various electrochemical systems [32, 36, 38, 39, 40, 41, 37]. This framework includes a multi-phase management as detailed in Neidhardt et al. [37], describing the spatial and temporal evolution of volume fractions of solid and liquid bulk phases. In the following, only the main features are summarized. Tab. 1 provides a summary of the physicochemical set of equations used for the simulations, and Tab. 2 summarizes chemical consituents and properties.

Fig. 1 gives a schematic overview of the 1D computational domain. The positive electrode (cathode in the 
Table 1: Overview over physical and electrochemical principles implemented in the electrochemical modeling framework DENIS. An exhaustive description of DENIS can be found in [36] and [37]. $s$ : index for species, $r$ : index for reactions; $k$ : index for reactant species, $l$ : index for product species; $\epsilon$ : dimensionless porosity; $\tau$ : a dimensionless tortuosity; $z_{s}$ : charge of species $s ; v_{r}^{k}$ : dimensionless stoichiometric coefficient of reactant species $k$ in reaction $r ; \mathrm{E}^{\mathrm{f}, \text { act }}$ : activation energy of forward reaction in $\frac{J}{m o l} ; \alpha$ : dimensionless transition coefficient; $\Delta G^{0}:$ Gibbs free energy in $\frac{J}{m o l}$, calculated from thermodynamic data of reactants and products; $R$ : gas constant in $\frac{J}{m o l K} ; T$ : temperature in $K ; A^{V}$ : volume specific reactive surface area in $\frac{m^{2}}{m^{3}} ; v_{\left(\mathrm{e}^{-}, \mathrm{r}\right)}$ : dimensionless stoichiometric coefficient of electrons for reaction $r$; $\mathrm{i}_{\mathrm{F}}$ : faradaic current density; $\mathrm{i}_{\mathrm{DL}}$ : current density due to double layer charge or discharge, assuming ideal capacitor behavior: $C^{V}$ volumetric capacity of double layer in $\frac{A s}{V m^{3}} ; \Delta \Phi$ : potential step in $V ; M_{s}$ : molar mass of species $s$ in $\frac{g}{m o l}, \rho_{s}$ : density of species $s$ in $\frac{g}{m^{3}} ; \epsilon^{\text {pore }}$ : dimensionless porosity of the anode. $\epsilon_{\mathrm{Li}_{2} S}$ is the sum of the volume fractions of the more reactive surface lithium sulfide fraction and the more passivated bulk lithium sulfide fraction at the anode side.

\begin{tabular}{|c|c|}
\hline \multicolumn{2}{|l|}{ Dissolved species and charge transport } \\
\hline Diffusion and migration in the liquid electrolyte: Nernst-Planck-Equation for dissolved species $s$ : & $\left.\frac{\partial c_{s}}{\partial t}\right|_{\text {transp }}=\frac{\partial}{\partial y}\left(D_{s}^{\mathrm{eff}}\left(\frac{\partial c_{s}}{\partial y}+\frac{z F c_{s}}{R T} \frac{\partial \Phi}{\partial y}\right)\right)$ \\
\hline Effective diffusion coefficient (dilute solution theory): & $D_{s}^{\text {eff }}=\frac{\epsilon}{\tau^{2}} D_{s}$ \\
\hline Electroneutrality and charge conservation: & $0 \stackrel{!}{=} \sum_{\mathrm{s}}\left(\mathrm{z}_{\mathrm{s}} \frac{\partial \mathrm{c}_{\mathrm{s}}}{\partial \mathrm{t}}\right)$ \\
\hline \multicolumn{2}{|l|}{ Reaction kinetics } \\
\hline Reaction rates: mass-action laws with reactants $\mathrm{X}$ and products $\mathrm{Y}$ & $R_{r}=k_{r}^{f} \prod_{k}\left(a\left(\mathrm{X}_{r}^{k}\right)^{v_{r}^{k}}\right)-k_{r}^{b} \prod_{l}\left(a\left(\mathrm{Y}_{r}^{l}\right)^{v_{r}^{l}}\right)$ \\
\hline Reaction constants: Modified Arrhenius expressions: relation to potential & $k^{f}=k_{0}^{f} T^{\beta} e^{\left(-\frac{E^{f}, a c t}{R T}\right)} e^{\left(-\frac{\alpha z F}{R T} \Delta \Phi\right)}$ \\
\hline Thermodynamic consistency & $K=\frac{k^{f}}{k^{b}}$ and $\Delta G^{0}=-R T \ln K \Rightarrow k^{b}=k^{f} e^{\frac{\Delta G^{0}}{R T}}$ \\
\hline Volumetric rates of change concentration $c_{s}$ of species $s$ & $\left.\frac{\partial c_{s}}{\partial t}\right|_{\text {reac }}=A^{V} \sum_{r}\left(v_{(s, r)} R_{r}\right)$ \\
\hline Faradaic current density at electrode-electrolyte interfaces & $i_{F}=F \sum_{r}\left(v_{\left(e^{-}, r\right)} R_{r}\right)$ \\
\hline Total current density: & $i=\int_{0}^{l_{\text {an }, \text { ca }}}\left(i_{F}+i_{D L}\right) d y$ with $i_{D L}=C^{V} \frac{\partial(\Delta \Phi)}{\partial t}$ \\
\hline Rates of change of dissolved species concentrations & $\frac{\partial c_{s}}{\partial t}=\left.\frac{\partial c_{s}}{\partial t}\right|_{\text {transp }}+\left.\frac{\partial c_{s}}{\partial t}\right|_{\text {reac }}$ \\
\hline \multicolumn{2}{|l|}{ Solid volume fractions in the electrodes } \\
\hline $\begin{array}{l}\text { Rates of change of volume fractions of species } s \\
\text { Feedback of volume fractions on electrode performance via reactive area } A^{V}\end{array}$ & $\begin{array}{l}\frac{\partial\left(\epsilon_{s}\right)}{\partial t}=A^{V} \frac{M_{s}}{\rho_{s}} \sum_{r}\left(v_{(s, r)} R_{r}\right) \text { with } \sum_{s}\left(\epsilon_{s}\right) \stackrel{!}{=} 1 \\
A^{V}=A_{0}^{V} f\left(\epsilon_{s}\right)\end{array}$ \\
\hline In this model, we use the heuristic expression for the anode reactive surface & $f\left(\epsilon_{s}\right)=\left(\frac{\epsilon_{\text {pore }}-\epsilon_{\mathrm{Li}_{2} \mathrm{~S}}}{\epsilon_{\text {pore }}}\right)^{3.5}$ \\
\hline
\end{tabular}

following) is a $15 \mu \mathrm{m}$ thick composite of carbon and pore space, the latter being filled with liquid electrolyte and solid reaction products (sulfur, lithium sulfide). The negative electrode (anode in the following) is in practice a lithium foil with a thickness of several tens to several hundreds of micrometers, which represents a large excess of lithium. The surface has a roughness of typically around $5 \mu \mathrm{m}$ as determined experimentally [42, 43, 44]. We model this situation by assuming a $5 \mu \mathrm{m}$ thick composite anode consisting of lithium metal and pore space. Here, the pore space represents the roughness; it is filled with liquid electrolyte in the pristine cell and can host solid decomposition products upon cycling (cf. below). Because of the lithium excess, the change in volume fraction of $\mathrm{Li}_{(\mathrm{s})}$ in the anode composite can be neglected, i.e. the lithium volume fraction is assumed constant.

As often assumed in electrochemical modeling, we assume infinite electronic conductivity in the lithium and graphite phases as well as in the current collectors.

Fig. 1 also schematically shows the assumed, simplified reaction mechanism of the Li/S battery with the reactions

$$
\begin{aligned}
8 \mathrm{~S}_{(\mathrm{s})} & \rightleftharpoons \mathrm{S}_{8} \\
\mathrm{~S}_{8}+4 \mathrm{e}^{-} & \rightleftharpoons 2 \mathrm{~S}_{4}^{2-}
\end{aligned}
$$

$$
\begin{aligned}
\mathrm{S}_{4}^{2-}+6 \mathrm{e}^{-} & \rightleftharpoons 4 \mathrm{~S}^{2-} \\
\mathrm{S}^{2-}+2 \mathrm{Li}^{+} & \rightleftharpoons \mathrm{Li}_{2} \mathrm{~S}_{(\mathrm{s})}
\end{aligned}
$$

on the cathode side and

$$
\mathrm{Li}_{(\mathrm{s})} \rightleftharpoons \mathrm{Li}^{+}+\mathrm{e}^{-}
$$

on the anode side. Note that all reactions are assumed to happen at interfaces between solid electrode components (sulfur, lithium sulfide, carbon, lithium) and the liquid electrolyte.

We choose to include the chemical dissolution of bulk sulfur to uncharged $S_{8}$ as first step, since we believe this process to be dominant over the direct ionization of bulk sulfur to $\mathrm{S}_{8}^{2-}$ : the latter process can only happen at the triple phase boundary between solid sulfur, carbon and electrolyte, which is assumed to be very small and unstable in Li/S cells. Purely chemical dissolution of bulk sulfur in TEGDME electrolyte is supported by experimental literature [e.g. 45] and other modeling work on lithium sulfur cells also assumes chemical dissolution of bulk sulfur into the electrolye as a first step [e.g. 31].

In addition to the reactions that describe the basic operation of the cell, here we add an as simple as possible description of the polysulfide shuttle effect: we allow for one redox step between two polysulfide 
species on the anode side. Additionally, we include precipitation of lithium sulfide on the anode side, enabling a loss of active material from the cathode to the anode and the associated capacity fading. Fig. 2 provides a schematic description of the resulting model, additionally including the reactions given in Eqs. 2, and 4 on the anode side.

Parameters and reactions for the presented $\mathrm{Li} / \mathrm{S}$ battery model can be found in Tab 2 . Interfaces and reactions that represent the polysulfide shuttle and the precipitation of lithium sulfide on the anode are given in brackets. To better capture long-term degradation effects, lithium sulfide on the anode side is assumed to consist of a reactive surface fraction and a partially passivated, less reactive bulk fraction. Reverse reaction rate coefficients are derived from thermodynamic consistency.

Dynamic simulations are carried out using either constant voltage $(\mathrm{CV})$ or constant current $(\mathrm{CC})$ as boundary condition. Before dynamic simulations are run, steady-state values for all state variables are calculated, starting with arbitrary, but consistent and electroneutral conditions. Steady-state values have been calculated with the shuttle effect turned off to avoid self-discharging of the model during equilibration.

While the supply of lithium is assumed unlimited, the deposition of solids on the anode surface influences the electrode's performance. This is implemented via a heuristic expression for $\mathrm{f}\left(\epsilon_{\mathrm{s}}\right)$ modulating the reactive surface area (see last Eq. in Tab. 1): The more precipitate is formed, the smaller the remaining active surface area.

\subsection{Model calibration}

\subsubsection{Base functioning of the Li/S battery}

The initial volume fraction of solid sulfur in the cathode was chosen such that the model yields the same C-rates as the experimental setup of [5] at corresponding current densities. As in [5], all C-rates are calculated based on a maximal theoretical capacity for a $\mathrm{Li} / \mathrm{S}$ cell of $1675 \mathrm{Ah} \mathrm{kg}^{-1}$ of sulfur.

Chemistry is assumed isothermal, that is, the activation energy of the Arrhenius expressions are set to effectively $0 \mathrm{~kJ} \mathrm{~mol}^{-1}$ and the Arrhenius temperature exponent $\beta$ is assumed to be 1 . This makes the Arrhenius pre-factor (which has been calibrated in the model)

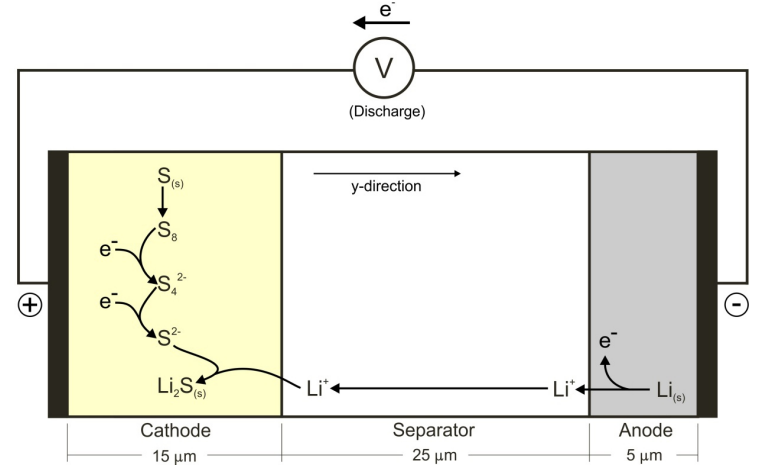

Figure 1: Computational domain and schematic of the basic Li/S battery reaction mechanism during discharge.

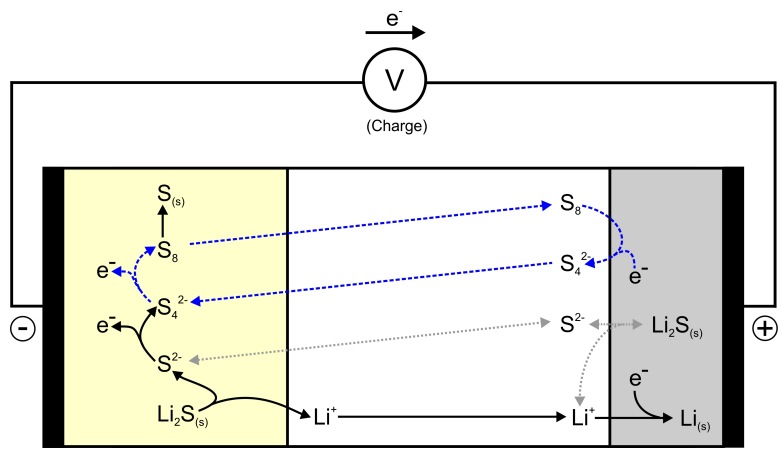

Figure 2: Representation of the polysulfide shuttle and loss of active material from the cathode to the anode in the presented model during charge. Black, solid lines: Regular charge; blue, dashed lines: polysulfide shuttle; grey, dotted lines: lithium sulfide precipitation at the anode side. 
Table 2: Parameters and reactions for the Li/S battery model (implemented in the electrochemical modeling environment DENIS, [36, 37]). $\Delta \mathrm{H}_{\mathrm{f}}^{0}$ : molar enthalpy of formation; $\mathrm{S}_{0}$ : standard molar entropy; $\mathrm{D}$ : diffusion coefficient of each species; $\mathrm{k}_{0}^{\mathrm{f}}$ : forward rate reaction rate coefficient; $\epsilon_{0}$ : initial volume fraction; $\rho$ : density; $\mathrm{A}_{\mathrm{V}}$ : specific area of interfaces; $\left({ }^{*}\right)$ : calibrated parameters; $(\circ)$ : a priori assumed parameters. Interfaces and reactions in the anode given in brackets describe the shuttle mechanism and can be turned off for comparison. T=298 K; $\mathrm{p}=101325 \mathrm{~Pa}$. Reaction kinetics in DENIS are evaluated by CANTERA [46]. Lithium sulfide on the anode side is assumed to consist of a reactive surface fraction Li $\mathrm{S}_{(\mathrm{s})}$ react. and a partially passivated, less reactive bulk fraction $\mathrm{Li}_{2} \mathrm{~S}_{(\mathrm{s})}^{\mathrm{pass}}$. Only the sum of both, $\mathrm{Li}_{2} \mathrm{~S}_{(\mathrm{s})}$, the total anodic lithium sulfide fraction, is given and discussed throughout the paper.

\begin{tabular}{|c|c|c|c|c|c|c|c|}
\hline \multirow[t]{16}{*}{ Cathode } & $\begin{array}{l}\text { Thickness } \\
\text { \# control volumes }\end{array}$ & $\begin{array}{l}15 \mu \mathrm{m}[5] \\
7\end{array}$ & & & & & \\
\hline & Bulk phases & $\epsilon_{0}$ & $\rho / \mathbf{k g ~ m}^{-3}$ & Species & $\Delta \mathrm{H}_{\mathrm{f}}^{\mathbf{0}} / \mathrm{kJ} \mathrm{mol}^{-1}$ & $\mathbf{S}^{0} / \mathbf{J ~ m o l}^{-1} \mathbf{K}^{-1}$ & $\mathbf{D} / \mathrm{m}^{2} \mathrm{~s}^{-1}$ \\
\hline & Sulfur & 0.2097 & $2.070 \cdot 10^{3}[47]$ & $S_{(s)}$ & $0.00[48]$ & $31.80[48]$ & $\mathrm{n} / \mathrm{a}$ \\
\hline & Carbon & 0.1000 & $2.260 \cdot 10^{3}[47]$ & $\mathrm{C}_{(\mathrm{s})}$ & \multicolumn{2}{|c|}{ non-reactive } & $\mathrm{n} / \mathrm{a}$ \\
\hline & Lithium sulfide $\left(\mathrm{Li}_{2} \mathrm{~S}\right)$ & $1.0 \cdot 10^{-20}$ & $1.640 \cdot 10^{3}[49]$ & $\mathrm{Li}_{2} \mathrm{~S}_{(s)}$ & -441.40 [49] & $0.00[49]$ & $\mathrm{n} / \mathrm{a}$ \\
\hline & Electrolyte & 0.6903 & $1.009 \cdot 10^{3}[50]$ & $\mathrm{C}_{10} \mathrm{H}_{22} \mathrm{O}_{5}$ & \multirow{2}{*}{\multicolumn{2}{|c|}{$\begin{array}{l}\text { non-reactive } \\
\text { non-reactive }\end{array}$}} & $1.0 \cdot 10^{-10}(\circ)$ \\
\hline & & & (without solutes) & $\mathrm{CFSO}_{3}^{-}$ & & & $1.8 \cdot 10^{-8}[51]$ \\
\hline & & & & $\mathrm{Li}^{+}$ & $-278.49[48]$ & $13.40[48]$ & $1.0 \cdot 10^{-10}[31,52]$ \\
\hline & & & & $\mathrm{S}_{8}$ & $-66.50(*)$ & $0.00(0)$ & $1.8 \cdot 10^{-9}[31]$ \\
\hline & & & & $\mathrm{S}_{4}^{2-}$ & $52.00(*)$ & $0.00(0)$ & $1.0 \cdot 10^{-10}[31]$ \\
\hline & & & & $S^{4-}$ & $133.00(*)$ & $0.00(\circ)$ & $1.0 \cdot 10^{-10}[31]$ \\
\hline & Interfaces & $A^{V} / \mathbf{m}^{2} \mathbf{m}^{-3}$ & Reactions & $\mathbf{k}_{0}^{\mathbf{f}}$ & & & \\
\hline & Electrolyte-Carbon-Sulfur- $\mathrm{Li}_{2} \mathrm{~S}$ & $1.0 \cdot 10^{5}$ & $\mathrm{~S}_{8} \rightleftharpoons 8 \mathrm{~S}_{(\mathrm{s})}$ & $1.25 \cdot 10^{-6}$ & $\mathrm{~s}^{-1}$ & & \\
\hline & & & $\mathrm{S}_{8}+4 \mathrm{e}^{-} \rightleftharpoons 2 \mathrm{~S}_{4}^{2-}$ & $1.00 \cdot 10^{-21}$ & & & \\
\hline & & & $\mathrm{S}_{4}^{2-}+6 \mathrm{e}^{-} \rightleftharpoons 4 \mathrm{~S}^{2-}$ & $1.00 \cdot 10^{-40}$ & & & \\
\hline & & & $\mathrm{S}^{4-}+2 \mathrm{Li}^{+} \rightleftharpoons \mathrm{Li}_{2} \mathrm{~S}_{(\mathrm{s})}$ & $2.00 \cdot 10^{-9}$ & $\left(\mathrm{kmol} \mathrm{m}^{-3}\right)^{-2} \mathrm{~s}^{-1}$ & & \\
\hline \multirow[t]{5}{*}{ Separator } & Thickness & $25 \mu \mathrm{m}[5,53]$ & & & & & \\
\hline & \# control volumes & 7 & & & & & \\
\hline & Bulk phases & $\epsilon_{0}$ & $\rho / \mathbf{k g ~ m}^{-3}$ & Species & & & \\
\hline & Electrolyte & 0.37 & $1.009 \cdot 10^{3}[50]$ & see cathode & & & \\
\hline & Separator & 0.63 & $1.009 \cdot 10^{3}(\mathrm{o})$ & none & & & \\
\hline \multirow[t]{12}{*}{ Anode } & Thickness & $5 \mu \mathrm{m}(\circ)$ & & & & & \\
\hline & \# control volumes & 7 & & & & & \\
\hline & Bulk phases & $\epsilon_{0}$ & $\rho / \mathbf{k g ~ m}^{-3}$ & Species & $\Delta \mathbf{H}_{\mathrm{f}}^{0} / \mathrm{kJ} \mathrm{mol}^{-1}$ & $\mathbf{S}^{0} / \mathbf{J ~ m o l}^{-1} \mathbf{K}^{-1}$ & $\mathbf{D} / \mathbf{m}^{2} \mathbf{s}^{-1}$ \\
\hline & Lithium & 0.63 & $0.534 \cdot 10^{3}[49]$ & $\mathrm{Li}_{(\mathrm{s})}$ & $0.00[49]$ & $29.10[49]$ & $1.0 \cdot 10^{-10}[31,52]$ \\
\hline & Electrolyte & 0.37 & $1.009 \cdot 10^{3}[50]$ & see cathode & & & \\
\hline & Lithium sulfide ( $\mathrm{Li}_{2} \mathrm{~S}$, react.) & $1.0 \cdot 10^{-20}$ & $1.640 \cdot 10^{3}[49]$ & $\mathrm{Li}_{2} \mathrm{~S}_{(s)}$ & $-441.40[49]$ & $0.00[49]$ & $\mathrm{n} / \mathrm{a}$ \\
\hline & Lithium sulfide ( $\mathrm{Li}_{2} \mathrm{~S}$, pass.) & $1.0 \cdot 10^{-20}$ & $1.640 \cdot 10^{3}[49]$ & $\mathrm{Li}_{2} \mathrm{~S}_{(s)}$ & $-442.40(*)$ & $0.00[49]$ & $\mathrm{n} / \mathrm{a}$ \\
\hline & Interfaces & $A^{V} / \mathbf{m}^{2} \mathbf{m}^{-3}$ & Reactions & $\mathbf{k}_{0}^{\mathbf{f}}$ & & & \\
\hline & Electrolyte-Lithium & $1.0 \cdot 10^{7}$ & $\mathrm{Li}_{(\mathrm{s})} \rightleftharpoons \mathrm{Li}^{+}+\mathrm{e}^{-}$ & $9.00 \cdot 10^{12}$ & \multirow{4}{*}{\multicolumn{3}{|c|}{$\begin{array}{l}\mathrm{s}^{-1} \\
\mathrm{~s}^{-1} \\
\left(\mathrm{kmol} \mathrm{m}^{-2}\right)^{-2} \mathrm{~s}^{-1} \\
\left(\mathrm{kmol} \mathrm{m}^{-2}\right)^{-2} \mathrm{~s}^{-1}\end{array}$}} \\
\hline & & & $\left(\mathrm{S}_{8}+4 \mathrm{e}^{-} \rightleftharpoons 2 \mathrm{~S}_{4}^{2-}\right)$ & $1.00 \cdot 10^{-114}$ & & & \\
\hline & Electrolyte- $\mathrm{Li}_{2} \mathrm{~S}$ & $1.0 \cdot 10^{3}$ & $\left(\mathrm{~S}^{2-}+2 \mathrm{Li}^{+} \leftrightharpoons \mathrm{Li}_{2} \mathrm{~S}_{(\mathrm{s})}^{\text {react. }}\right)$ & $2.00 \cdot 10^{-9}$ & & & \\
\hline & & & $\left(\mathrm{S}^{2-}+2 \mathrm{Li}^{+} \leftrightharpoons \mathrm{Li}_{2} \mathrm{~S}_{(\mathrm{s})}^{\text {pass }}\right)$ & $6.00 \cdot 10^{-10}$ & & & \\
\hline
\end{tabular}

the effective forward rate coefficient. The symmetry factor $\alpha$ is assumed to be 0.5 for all charge-transfer reactions. All simulations are run at room temperature and ambient pressure $(T=298 \mathrm{~K}$ and $\mathrm{p}=101325 \mathrm{~Pa})$.

All kinetic parameters (i.e. forward reaction rate coefficients $\mathrm{k}_{0}^{\mathrm{f}}$ ) and thermodynamic parameters marked with $\left(^{*}\right)$ in Tab. 2 were manually calibrated such that the modeled discharge curves fit experimental discharge curves from literature [5] at the same current densities and C-rates (as mentioned above, the sulfur content of the modeled cathode has been chosen to match experimental C-rates at respective current densities). The model parameters were calibrated by comparing model output to experimental discharge curves for 0.5 and $24.5 \mathrm{~A} \mathrm{~m}^{-2}$ only. The discharge at $0.5 \mathrm{~A} \mathrm{~m}^{-2}$ was mainly used for calibration of thermodynamic parameters, while the discharge at $24.5 \mathrm{~A} \mathrm{~m}^{-2}$ was mainly used for kinetic parameters. No other current densities have been used for calibration.

As for the anode, the kinetics of the lithium-ion supply reaction is chosen sufficiently fast as to not pose any rate limitation, keeping anode kinetic overpotentials negligible. Also, for the currents used in this study, the transport of all dissolved species in the liquid electrolyte is fast enough to not make a significant contribution to the overpotential.

\subsubsection{Shuttle mechanism and battery degradation}

In general, there are two cases where the polysulfide shuttle effect becomes apparent. At low charging current densities, seemingly infinite charging with constant charge current density can occur, while at higher current densities, the shuttle effect acts as a 
parasitic side reaction increasing the charge capacity over the discharge capacity. The kinetic parameter of the electron-transfer reaction on the anode side representing the shuttle effect (reaction 2) has been calibrated such that the threshold current density for the seemingly infinite charging behavior of approx. $300 \mathrm{~mA} \mathrm{~m}^{-2}$ is similar to the threshold for this phenomenon found for experimental systems [35].

Cell degradation due to cycling was calibrated as well. By adapting the feedback of the precipitation of solids on the anode active surface (last Eq. in Tab. 1), the voltage drop for the main discharge-plateau with higher cycle numbers could be adjusted. With a $5 \mu \mathrm{m}$ thick anode, the anode porous volume is large enough to allow for sufficient transport of solid material from cathode to anode to reproduce capacity fading.

\section{Results and Discussion}

\subsection{Simulated discharge at different $C$-rates}

Simulated discharge behavior of the model is shown in Figs. 3 and 4 for five different discharge current densities. Current densities and C-rates are equivalent to experimental discharge curves from [5], so simulation results and experimental results can be directly compared.

Panel a) of Fig. 3 shows the fit between simulation and experiment with respect to discharge voltage curves. For the $0.5 \mathrm{~A} \mathrm{~m}^{-2}$ case, both voltage plateaus commonly observed in Li/S cells match reasonably well between experiment and simulation. Also the capacity at which the voltage steeply declines, i.e. the end of discharge, fits reasonably well between experiment and simulation for the $0.5 \mathrm{~A} \mathrm{~m}^{-2}$ and the $24.5 \mathrm{~A} \mathrm{~m}^{-2}$ cases. Even though the model has not been calibrated for current densities between those bracketing values, the fit for the remaining current densities is good as well, which instills considerable confidence in the model being able to represent a real cell with sufficient accuracy.

Not very well represented in our simulations are the curvature of the voltage evolution at the end of the second plateau phase, and particularly the transition from the the first voltge plateau to the second voltage plateau. The mismatch of the curvature of the voltage curve at the end of discharge can most likely be explained by kinetic effects: In the real cell, the overpotential rises because of various processes such as

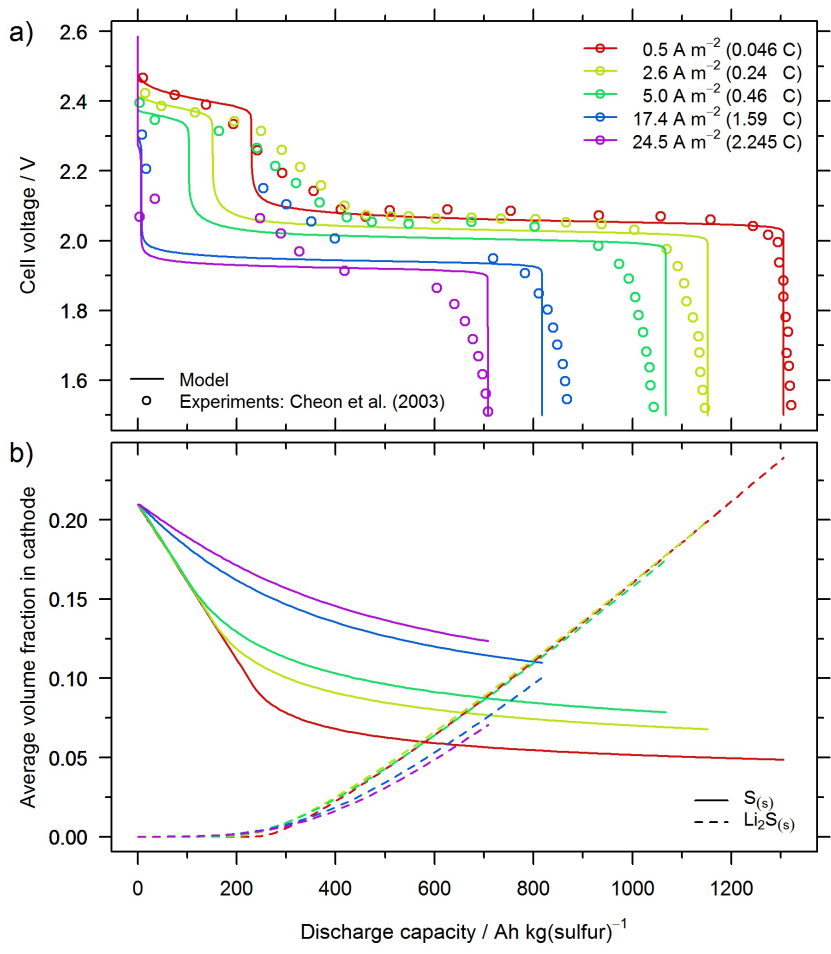

Figure 3: Discharge behavior of base model: discharge curves and average solid volume fractions. As in [5], C-rate values are calculated based on a maximum theoretical capacity for the $\mathrm{Li} / \mathrm{S}$ cell of $1675 \mathrm{Ah}$ $\mathrm{kg}^{-1}$ of sulfur $[7,15,4]$.

$\mathrm{Li}_{2} \mathrm{~S}$ deposition on electrochemically active surfaces, pore clogging, and growth of solid blocks of $\mathrm{Li}_{2} \mathrm{~S}$ with increased resistance. Capturing these effects would require a $3 \mathrm{D}$ model or at least a $1 \mathrm{D}$ model coupled to a $3 \mathrm{D}$ representative volume, which is beyond the scope of this paper. The transition from the first to the second discharge voltage plateau in lithium sulfur cells happens concurrently with the depletion of solid sulfur and the start of the formation of solid lithium sulfide. The biggest contribution to the mismatch in this region is most likely the lack of detailed treatment of nucleation and growth of solid particles in our model. However, for $\mathrm{Li} / \mathrm{S}$ cells, there is no known source for the additional parameters required for a detailed, complex description of nucleation and growth. Neglecting a detailed treatment of nucleation and growth of solid particles allowed us to keep the model computationally tractable and the results more interpretable concerning the process we want to investigate: the shuttle effect. 
While the model might be extended to improve the fit, our objective is to set up an "as simple as possible" model that still can reproduce the macroscopic behavior of a Li/S cell (including shuttle-effect and degradation) fairly well. We therefore believe that the choice of effects to be included in the model is reasonable and the obtained agreement between experimental results and our simulations is satisfactory.

Fig. $3 \mathrm{~b}$ ) shows the evolution of volume fractions of solid sulfur $\left(\mathrm{S}_{(\mathrm{s})}\right)$ and solid lithium sulfide $\left(\mathrm{Li}_{2} \mathrm{~S}_{(\mathrm{s})}\right)$ in the cathode. In our simulations, not all of the elemental sulfur is dissolved at the end of the discharge. For $0.5 \mathrm{~A} \mathrm{~m}^{-2}$ about $23 \%$ of elemental sulfur is unused (i.e., solid sulfur not dissolved), $63 \%$ of elemental sulfur is already converted to $\mathrm{Li}_{2} \mathrm{~S}$, and $14 \%$ is still present as dissolved polysulfides at the end of the discharge. Progressively, less elemental sulfur is utilized with higher discharge current densities, reducing the practical capacity of the battery. This is consistent with experimental findings by [27]. However, it is different from the behavior of the model presented in [32], where an intermediate regime of completely dissolved solids is identified. Also there are different experimental results for various kinds of cells, e.g. summarized by [4]. This indicates that there still is a lack of complete knowledge of the exact discharge mechanism in $\mathrm{Li} / \mathrm{S}$ cells. Most likely, there will be a threshold current density, below which all sulfur is dissolved and above which some solid sulfur remains after discharge. For the examination of the effects of the polysulfide shuttle presented here, however, the percentage of elemental sulfur dissolution is not of vital importance, and was not further investigated.

Fig. 4 shows average concentrations (denoted in the followig by square brackets "[]") of dissolved species in the cathode for the five discharge simulations. $\left[\mathrm{S}_{8}\right]$ roughly follows the voltage curve, exhibiting a first plateau followed by a steep decrease, a second plateau, and finally a steep decrease again. $\left[\mathrm{S}_{4}^{2-}\right]$, however, initially rises and stays at roughly $1 \mathrm{kmol} \mathrm{m}^{-3}$ with little differences for all discharge current densities for almost the whole duration of the discharge. Only with the final decrease of the cell voltage, $\left[\mathrm{S}_{4}^{2-}\right]$ steeply deccreases (to values lower than $\left[\mathrm{S}_{8}\right]$ ). The way the reaction mechanism was formulated, reaction (3) provides the biggest part of the electron accepting capability, namely six electrons per molecule of $\mathrm{S}_{4}^{2-}$. It can thus be argued that the end of the discharge (i.e. the final steep voltage decrease) is mainly a result of the decrease in $\left[\mathrm{S}_{4}^{2-}\right]$, with only a minor influence of the decrease of the $S_{8}$

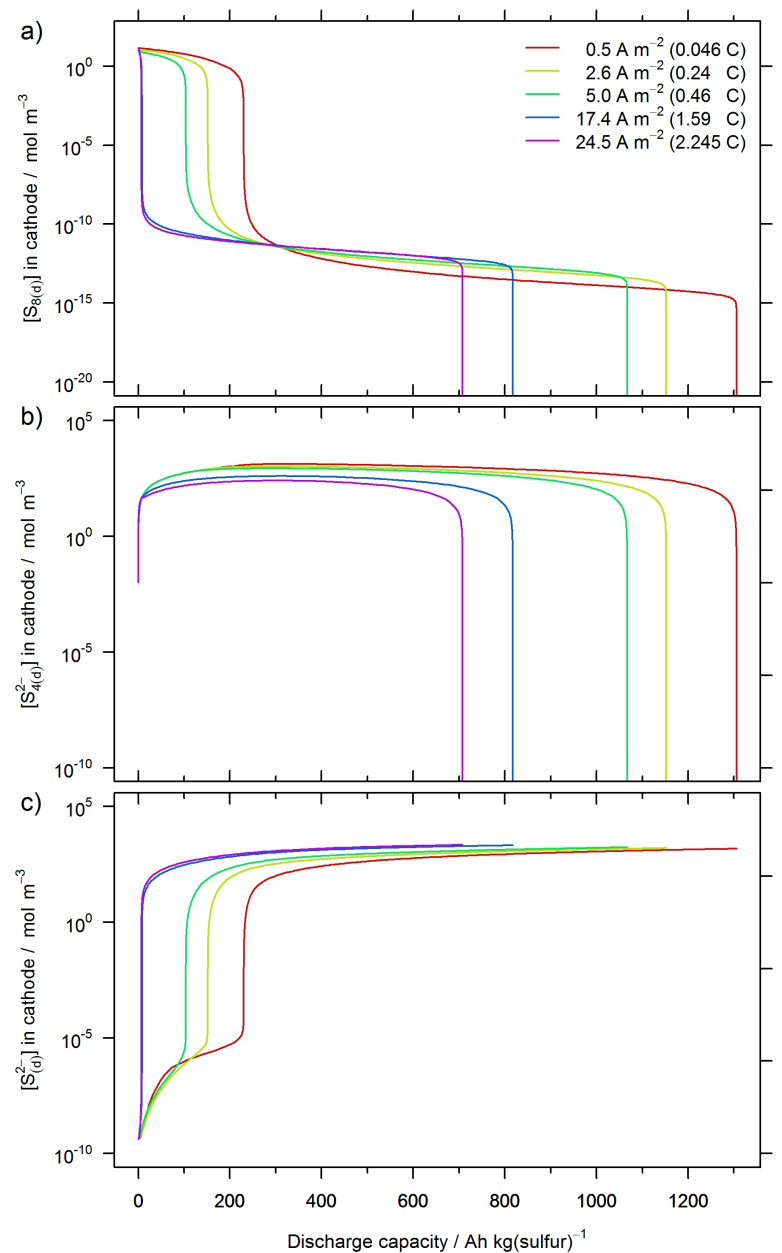

Figure 4: Discharge behavior of base model: concentrations of key species in the electrolyte averaged over the cathode volume.

concentration.

Since reaction (4) does not consume electrons, it is to be expected that the cell voltage does not depend on $\left[\mathrm{S}^{2-}\right]$, allowing for higher values of $\left[\mathrm{S}^{2-}\right]$ during the end of the discharge. Our simulation results confirm this: $\left[\mathrm{S}^{2-}\right]$ increases over the course of the discharge of the battery, reaching maximal values towards the end of the discharge, hinting at a kinetic limitation of $\mathrm{Li}_{2} \mathrm{~S}$ formation. Thus, sulfur that is not fully converted to $\mathrm{Li}_{2} \mathrm{~S}$ yet is accumulating as $\mathrm{S}^{2-}$ towards the end of the discharge. Virtually all of the $14 \%$ of sulfur still present in the form of dissolved polysulfides at the end of the simulated discharge is present in the form of $\mathrm{S}^{2-}$. 


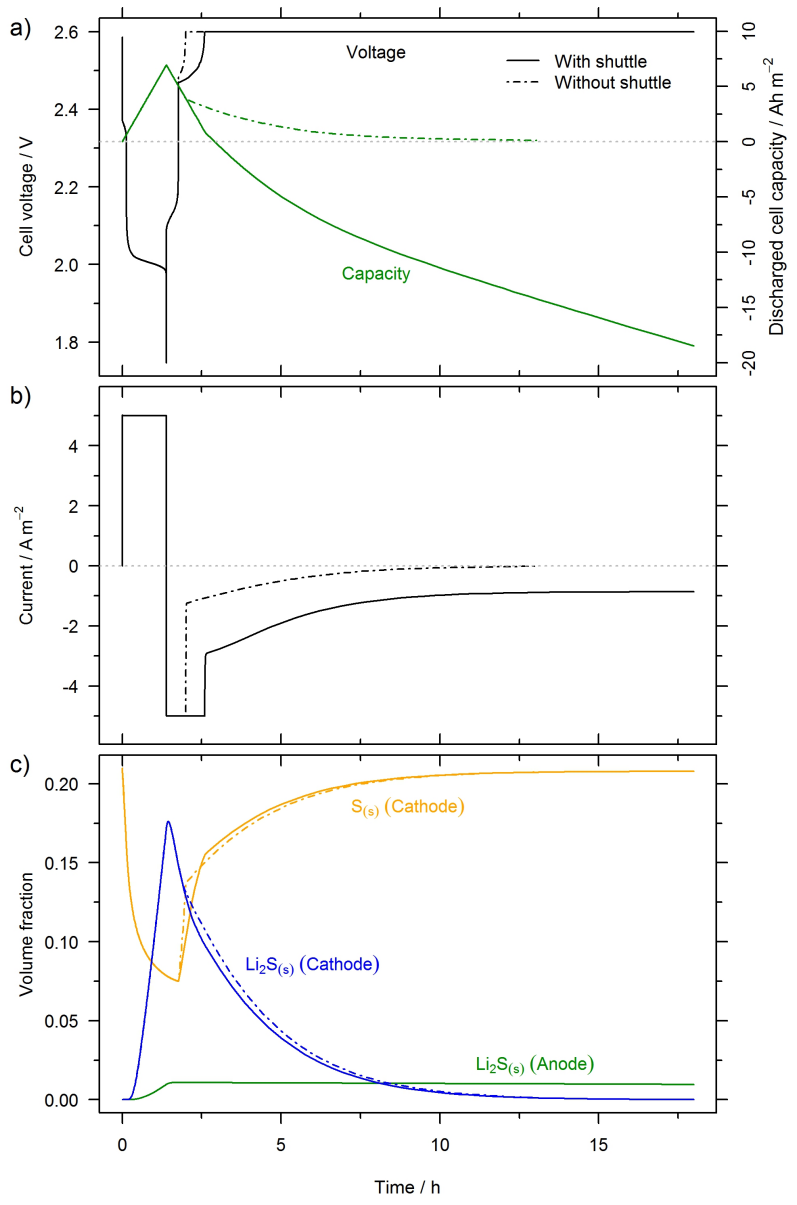

Figure 5: Comparison of discharge (CC) and charge (CCCV) simulations without and with shuttle effect $\left(+/-5 \mathrm{~A} \mathrm{~m}^{-2}=0.46 \mathrm{C}, 2.6 \mathrm{~V}\right.$ cut-off). The horizontal, gray, dotted lines mark the zero points of the cell discharge capacity (panel a, axis on the right) and the charge current density (panel b), respectively.
3.2. The influence of the polysulfide shuttle on cell operation

Fig. 5 shows a comparison of discharge and charge simulation runs (CC discharge and CCCV charge, +/$5 \mathrm{~A} \mathrm{~m}^{-2}$ or $0.46 \mathrm{C}$ ) including the polysulfide shuttle (solid lines) and with the polysulfide shuttle turned off (dash-dotted lines). It can be seen that the discharge is virtually not affected by the polysulfide shuttle. Differences become apparent, however, during simulated charging. Fig. 5 a) shows that the second charging voltage plateau becomes significantly enlarged by the polysulfide shuttle, which is consistent with the inclusion of the redox step expressed by reaction (2) at the anode side, as this reaction on the cathode side is the predominant process during the second charging voltage plateau.

In the hypothetical case with the shuttle turned off, the cell becomes fully charged in the $\mathrm{CV}$ regime quicker than in simulations using the model including the shuttle: the current density levels off much quicker for the simulation without shuttle than for the simulation with shuttle (Fig. 5 b)). Effectively, the polysulfide shuttle acts as parasitic reaction by internally transporting electrons from the anode to the cathode and thus being in competition with the actual charging process of the battery which removes electrons from the cathode and stores them in the anode. This can be seen in our simulation as a negative discharge capacity during charging and a very slowly decreasing charge current density during the $\mathrm{CV}$ regime (solid lines in Figs. 5 a) and b)). In fact, due to the shuttle effect, the zero current cutoff is not reached during the the simulation including the shuttle effect: a "shuttle current" of about $1 \mathrm{~A} \mathrm{~m}^{-2}$ remains in the $\mathrm{CV}$ regime until the end of the simulation.

The temporal evolution of the volume fractions of solid sulfur $\left(\mathrm{S}_{(\mathrm{s})}\right)$ and solid lithium sulfide $\left(\mathrm{Li}_{2} \mathrm{~S}_{(\mathrm{s})}\right)$ in the cathode and the total volume fraction of solid $\mathrm{Li}_{2} \mathrm{~S}_{(\mathrm{s})}$ in the anode (Fig. $5 \mathrm{c}$ )), again shows that the discharge of the cell is virtually not influenced by the polysulfide shuttle effect (except for a slight buildup of solid lithium sulfide on the anode side: solid, green line in Fig. 5 c)). For the charging, however, slight differences are readily visible, while the final values (i.e. of a "fully charged cell") of both $\mathrm{S}_{(\mathrm{s})}$ and $\mathrm{Li}_{2} \mathrm{~S}_{(\mathrm{s})}$ in the cathode are roughly equal for the simulation runs with and without the shuttle effect.

The parasitic effect of the polysulfide shuttle becomes more severe with increasing charge-current-density: to 
reach a fully charged battery in terms of sulfur volume fraction at the cathode in our simulations, an excess charge capacity of approximately $40 \%$ of the initial discharge capacity is needed at $5 \mathrm{~A} \mathrm{~m}^{-2}$ charge current (Fig. 5 a)). In our simulations, this percentage is lower at lower charge current densities and higher at higher charge current densities (results not shown). The reason for this behavior is most likely kinetic competition, where higher currents favor the shuttle reaction. Increasing parasitic losses due to the shuttle effect with higher current densities are roughly consistent with experimental findings reported by Mikhaylik et al. [35].

\subsection{Infinite charging}

Experimental evidence (e.g. [35]) suggests that at very low charging current densities (lower than in Fig. 5; absolute values lower than any of the discharge current densities in Fig. 3), there is a threshold below which the polysulfide shuttle is dominant over the actual charging of the battery. This results in a seemingly "infinite" charging behavior at constant current densities, where the voltage levels off, never reaching the cut-off voltage. In the past, this attribute of $\mathrm{Li} / \mathrm{S}$ cells has even been heralded as an "intrinsic overcharge protection" feature.

Our model reproduces this behavior: Fig. 6 shows six different $\mathrm{CC}$ charge-simulations following a $0.5 \mathrm{~A} \mathrm{~m}^{-2}$ $\mathrm{CC}$ discharge. Four simulated charge current densities are below the infinite charging threshold for our model, and two simulated charge current densities are above this threshold, which is bracketed by $0.2 \mathrm{~A} \mathrm{~m}^{-2}$ and $0.4 \mathrm{~A} \mathrm{~m}^{-2}$. For the two charge current densities above the threshold ( 0.4 and $\left.1.0 \mathrm{~A} \mathrm{~m}^{-2}\right)$, the cut-off voltage of $2.6 \mathrm{~V}$ is reached with a nearly vertical voltage increase, which is a result of steeply decreasing $\left[\mathrm{S}^{2-}\right]$ and $\left[\mathrm{S}_{4}^{2-}\right]$ values (see Appendix A for details). In the cases below the threshold $\left(0.20,0.08,0.04\right.$, and $\left.0.02 \mathrm{~A} \mathrm{~m}^{-2}\right)$ both voltage plateaus are elongated. For the cases $0.2,0.08$ and $0.04 \mathrm{~A} \mathrm{~m}^{-2}$, the second voltage plateau is extended indefinitely, stabilizing at voltage values increasingly higher with increasing charge current density, which is consistent with experimental findings [35]. In the $0.02 \mathrm{~A} \mathrm{~m}^{-2}$ case, the first voltage plateau is overproportionally extended: an effect that becomes more prominent with even lower charge current densities (not shown).

Figs. 6 b) and c) show volume fractions of solid sulfur $\mathrm{S}_{8(\mathrm{~s})}$ (panel b) and solid $\mathrm{Li}_{2} \mathrm{~S}_{(\mathrm{s})}$ (panel c) for the cathode (solid lines) and the anode (dashed lines,

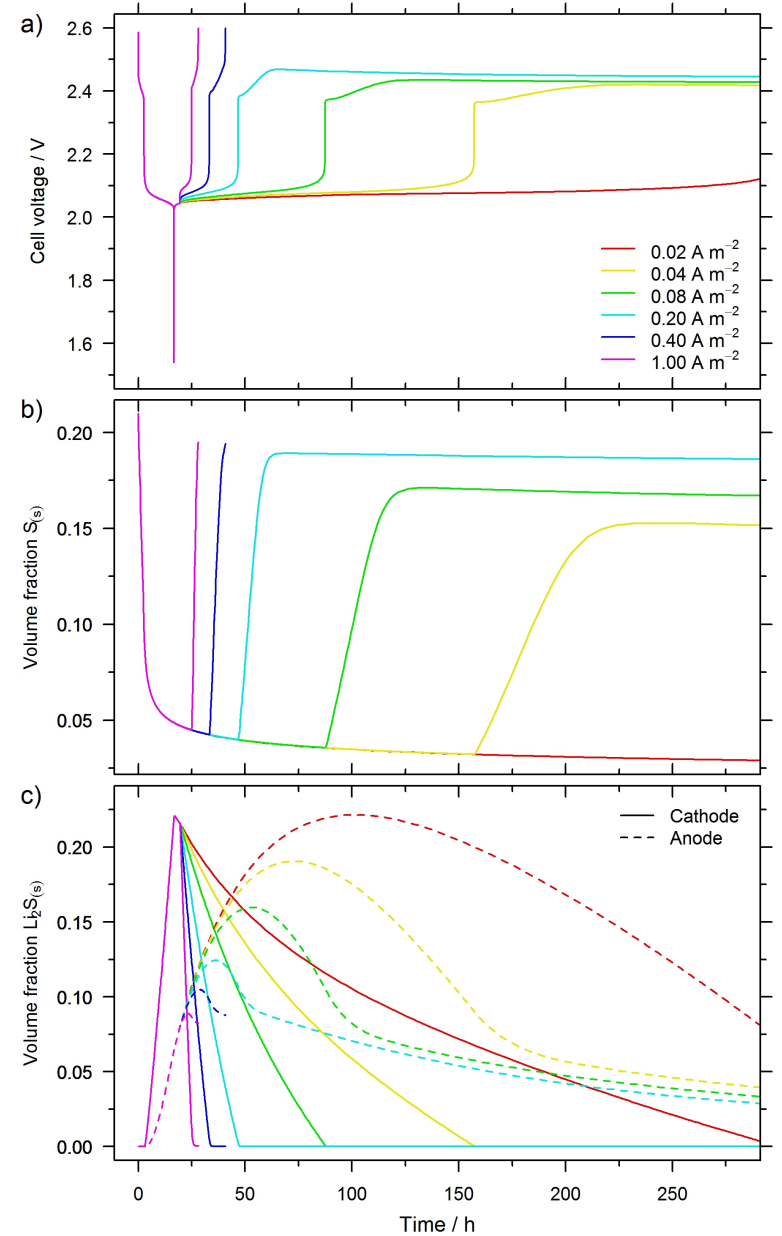

Figure 6: Analysis of infinite-charging branch: cell voltage and solid volume fractions on anode and cathode side $\left(0.5 \mathrm{~A} \mathrm{~m}^{-2} \mathrm{CC}\right.$ discharge, followed by $\mathrm{CC}$ charges with the current densities given in the legend). For convenience, only the sum of the more reactive surface fraction and the less reactive bulk fraction of solid $\mathrm{Li}_{2} \mathrm{~S}$ is given for the ande side in panel c). Also for convenience, current densities are reported as positive values in the figure legends, in the simulation, however, the current densities are negative for the charging case. 
$\mathrm{Li}_{2} \mathrm{~S}_{(\mathrm{s})}$ only) for all charging scenarios. It can be seen that the volume fraction of $S_{8(s)}$ initially continues to decrease. This is due to the fact that dissolution or precipitation of solid sulfur (reaction 1) does not consume or produce electrons and thus does not directly depend on the current density. After a discharge the concentration of dissolved sulfur $\left[\mathrm{S}_{8}\right]$ is significantly lower than the equilibrium concentration, therefore solid sulfur dissolution intially continues. The interplay of redox reactions between the dissolved species (that do depend on current densities) first causes a significant rise in $\left[\mathrm{S}_{8}\right]$ before solid sulfur dissolution stops and is eventually reversed (see Appendix A for details).

After the initial continued decrease, the volume fraction of $S_{8(s)}$ rapidly increases for all cases. For the charge current densities above the "infinite" charging threshold, it steeply increases together with rapidly rising voltage. For the three highest cases below the threshold, it reaches and remains at a plateau that increases with increasing current density. In the $0.02 \mathrm{~A}$ $\mathrm{m}^{-2}$ case this plateau is not reached, as is the second charging voltage plateau.

The volume fraction of $\mathrm{Li}_{2} \mathrm{~S}_{(\mathrm{s})}$ in the cathode decreases immediately as charging commences, while in the anode, it initially increases. Although lithium sulfide precipitation is not directly dependent on charge/discharge current density and the concentration of dissolved monosulfide $\left[\mathrm{S}^{2-}\right]$ is rather high after a discharge of the battery, the observed disparity between cathode and anode here seems to be caused by the lower specific reactive surface area value assumed for the anode: there lithium sulfide deposition slowly proceeds as long as $\left[\mathrm{S}^{2-}\right]$ and $\left[\mathrm{Li}_{(\mathrm{s})}^{+}\right]$(not shown) are still high enough and the volume fraction of solid lithium sulfide is still low enough. Towards the end of the simulation time, a concurrent dissolution of solid lithium sulfide in both electrodes is observed, with the dissolution at the anode side showing a concave shape due to the transition of dissolution from the reactive surface fraction to the more passivated bulk fraction of $\mathrm{Li}_{2} \mathrm{~S}_{(\mathrm{s})}$.

The solid volume fractions of $\mathrm{Li}_{2} \mathrm{~S}$ in the carthode steadily decrease and return back to zero at about the time solid sulfur precipitation starts to increase (panels b and c) of Fig. 6.

Based on the presented model, the following mechanistic interpretation of the shuttle effect can be derived. During charging, electrons enter the anode via the external circuit and reduce $\mathrm{S}_{8}$ to $\mathrm{S}_{4}^{2-}$ on the anode

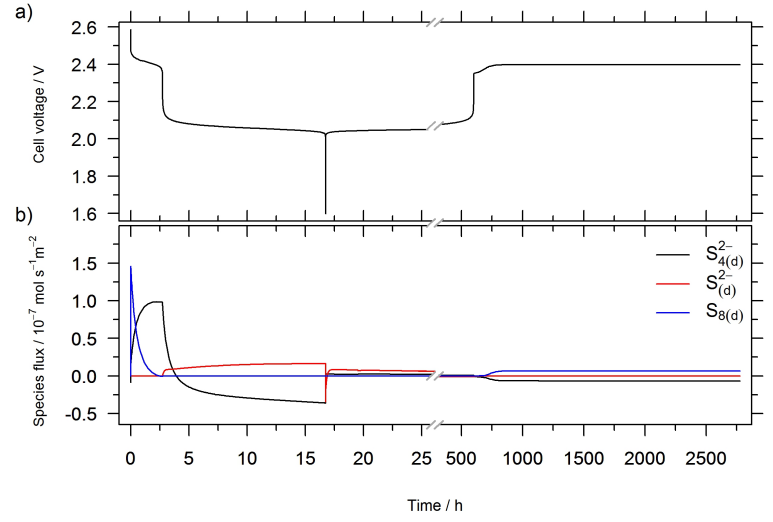

Figure 7: Analysis of infinite-charging branch. Panel a): cell voltage, panel b): species fluxes $\left(\mathrm{mol} \mathrm{m}^{-2} \mathrm{~s}^{-2}\right)$ in separator center $\left(0.5 \mathrm{~A} \mathrm{~m}^{-2}\right.$ $\mathrm{CC}$ discharge, followed by a $0.01 \mathrm{~A} \mathrm{~m}^{-2} \mathrm{CC}$ charge). Positive flux means transport from the positive (sulfur) electrode to the negative (lithium) electrode.

surface. $\mathrm{S}_{4}^{2-}$ is then transported to the cathode where it gets oxidized back to $S_{8}$, realeasing the electrons which leave the cathode via the external circuit. $\mathrm{S}_{8}$ is subsequently transported back to the anode (cf. schematics in Fig. 2). In near steady state conditions such as during the "infinite" charging scenarios, this entails a continuous and constant transport of $\mathrm{S}_{8}$ from the cathode to the anode and a continuous and constant transport of $\mathrm{S}_{4}^{2-}$ from the anode to the cathode: Fig. 7 shows the transport of dissolved species across the separator center, with positive values indicating transport from cathode to anode. In the right part of the figure, it can be seen that during the voltage plateau phase, there is a net transport of $S_{8}$ from the cathode to the anode and a net transport of $\mathrm{S}_{4}^{2-}$ from the anode to the cathode. The fact that the absolute value of $\mathrm{S}_{4}^{2-}$ transport is not exactly double the absolute value of $\mathrm{S}_{8}$ (which would be stoichiometrically correct for the transport of the same amount of electrons $\left(S_{4}^{2-}\right)$ or electron-vacancies $\left(S_{8}\right)$ ), indicates that the system is not fully in steady state yet.

\subsection{Battery cycling and degradation}

Finally, cycling simulations have been performed as well: Fig. 8 shows ten cycles of $0.5 \mathrm{~A} \mathrm{~m}^{-2} \mathrm{CC}$ discharges alternating with $-0.5 \mathrm{~A} \mathrm{~m}^{-2} \mathrm{CC}$ charges, which are cut off at $2.6 \mathrm{~V}$. Fig. 8 a) depicts volume fractions of $\mathrm{S}_{8(\mathrm{~s})}$ and $\mathrm{Li}_{2} \mathrm{~S}_{(\mathrm{s})}$ in the cathode. While the general shape of the temporal evolution of both solid volume fractions remains the same, it can be seen that there is a net loss of active material from 


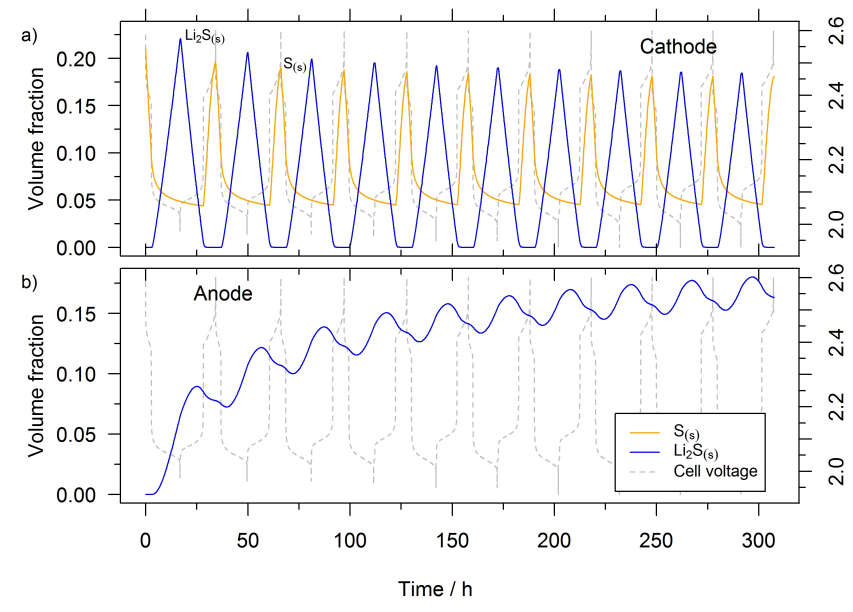

Figure 8: Cycling with polysulfide shuttle: cell voltage and volume fractions in cathode and anode over ten cycles.

the cathode, as the maximum values of both solid volume fractions decrease from cycle to cycle. The loss of active material from the cathode is due to irreversible transport to the anode, where the lithium sulfide solid volume fraction increases over time (Fig. 8 b)). The minimum value of the volume fraction of $S_{8(s)}$ in the cathode, however, remains the same for all cycles.

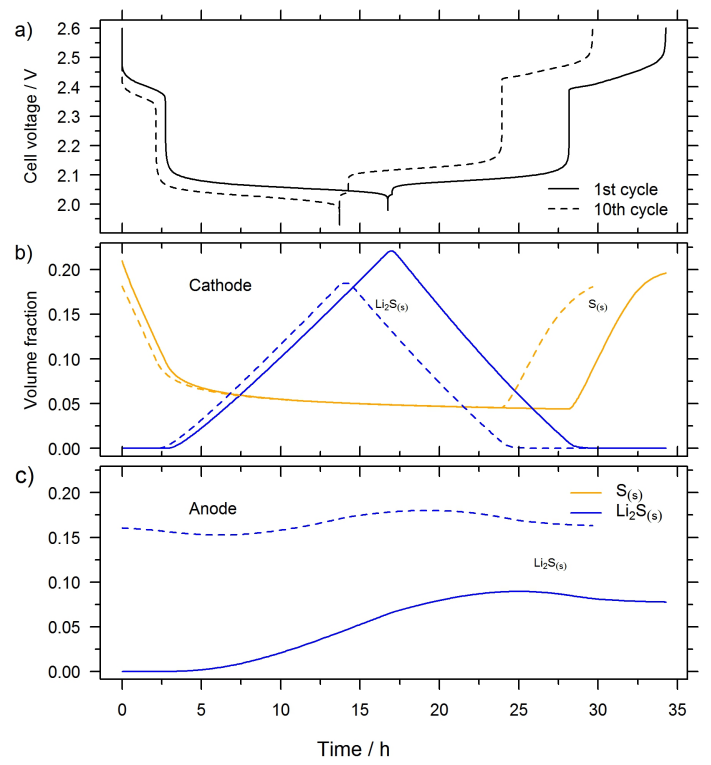

Figure 9: Cycling with polysulfide shuttle: volume fractions in cathode and anode: comparison between $1^{\text {st }}$ and $10^{\text {th }}$ cycle.

While the general shape of the voltage curve for both discharge and charge also remains the same over all cycles, there are marked differences between the first and the tenth cycle (Fig. 9 a)): both voltage plateaus are significantly decreased in the tenth cycle as a result of precipitation of solids on the anode surface and a resulting decrease of the anode active surface accompaonied by a higher anode overpotential (not shown). Also, क्ष the the steep voltage decrease at the end of the second $\overline{\bar{\delta}}$ discharge voltage plateau occurs significantly earlier in the tenth cycle than it does in the first, which is a result of the loss of active material from the cathode to the anode, cf. Figs. 9 b) and c).

The general shape of the temporal evolution of solids in the cathode (Fig. 9 b)) is the same for the first and tenth cycle, the tenth cycle merely starts at a lower value for the $S_{8(s)}$ volume fraction, resulting in a lower $\mathrm{Li}_{2} \mathrm{~S}_{(\mathrm{s})}$ volume fraction value. On the anode side, there are more pronounced differences (Fig. 9 c)): in the tenth cycle, the lithium sulfide volume fraction is permanently higher than in the first cycle and the amplitudes of change have decreased.

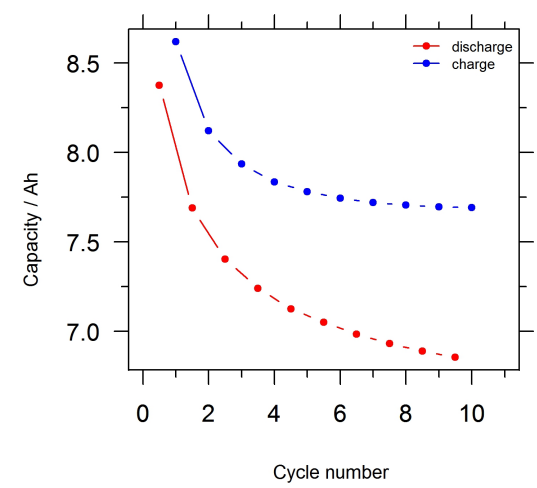

Figure 10: Cycling with polysulfide shuttle and precipitation at the anode: Discharge and charge capacity versus cycle number.

The loss of active material from the cathode results in capacity fading for the simulated cell during cycling (Fig. 10, red dots and dashes). Discharge capacity decreases by roughly $18 \%$ from about 8.4 Ah to about 6.9 Ah within ten cycles. The capacity decrease is rather steep during the first four cycles and levels off afterwards, which is qualitatively similar to experimental cycling behavior of cells with a high content of liquid electrolyte [54]. Note, however, that in our simulations, the capacity loss is purely due to transport of active material from the cathode to the anode. Other proposed $\mathrm{Li} / \mathrm{S}$ battery capacity fading mechanisms, e.g., due to 
cathode performance loss by irreversible further oxidation of $\mathrm{Li}_{2} \mathrm{~S}$ and $\mathrm{Li}_{2} \mathrm{~S}_{2}$ to $\mathrm{Li}_{\mathrm{x}} \mathrm{SO}_{\mathrm{y}}$ compounds [55] or changes to the microstructure, are not implemented in the model, and may additionally contribute to capacity fading.

The simulated cycling of our modeled cell can also reproduce the low coulombic efficiency often associated with liquid-electrolyte $\mathrm{Li} / \mathrm{S}$ cells: it is represented by the difference between the discharge capacities (red curve) and the charge capacities (blue curve) in Fig. 10. In our simulation, the coulombic efficiency decreases with increasing cycle number, as the difference between discharge and charge capacity increases.

\section{Conclusions and outlook}

Lithium-sulfur batteries are a promising candidate for high-energy density lithium batteries for stationary, mobile, and portable applications. We have presented a comprehensive modeling and simulation study of the electrochemical behavior during cell operation under typical conditions.

With an instructively simple four-step sulfur reduction mechanism and a simple representation of the polysulfide shuttle (cf. Fig. 2), the agreement of our simulations with experimental discharge curves is still very good. We are able to reproduce the macroscopic effects of the polysulfide shuttle commonly seen in liquid-electrolyte Li/S batteries: "infinite" charging at low constant current densities, low coulombic efficiency, and capacity fading due to loss of active material from the cathode to the anode. This provides insights into the basic underlying principles and makes the presented model not only a suitable tool for investigation and interpretation of $\mathrm{Li} / \mathrm{S}$ cell experimental data but also a powerful base model for further, more complex model studies focusing on specific details of liquid-electrolyte Li/S cells.

There is still a widespread need for research, of which our modeling analysis is only a small step. Liquid-electrolyte Li/S cells will be improved by investigating, understanding and avoiding the shuttle effect and other degaradation mechanisms like, e.g., irreversible side reactions inactivating lithium sulfide as detailed in [55]. Additionally, significant research activity is directed towards microstucturing the electrodes to avoid transport of polysulfides alltogether, e.g., using core/shell or yolk/shell architecture $[56,57,58,59,30]$.
Furthermore, all-solid-state $\mathrm{Li} / \mathrm{S}$ batteries are being investigated [60], and might prove to be a promising alternative to liquid-electrolyte cells.

Additionally, for Li/S cells as for all conversion materials, crystallization of solids and the growth of solid phases is very important. This issue has not been addressed in great detail in our model study, and further research into nucleation and growth of solids, e.g., along the lines of [41] and [61] who worked on the related problem of nucleation and growth of $\mathrm{Li}_{2} \mathrm{O}_{2}$ in $\mathrm{Li} / \mathrm{O}_{2}$ batteries, is a promising way forward.

\section{Acknowledgements}

The authors thank Klaus Göckelmann for technical support with DENIS and general computational and informatical expertise.

The research leading to these results has received funding from the European Union $7^{\text {th }}$ Framework Programme FP7/2007-2013 under grant agreement $n^{\circ}$ 314282 (LISSEN).

David N. Fronczek acknowledges financial support by the Foundation of the German Industry (sdw).

\section{Appendix A. Temporal evolution of dissolved species in cathode and anode during "infinite" charging}

During the infinite charging situation, $\left[\mathrm{S}_{8}\right]$ values reach high plateau values (for the cases below the "infinite" charging threshold: $0.20,0.08$, and $0.04 \mathrm{~A} \mathrm{~m}^{-2}$ ) at the time the voltage plateaus are reached, after a steep increase from comparatively low values, and a small, lower plateau, tracking the voltage increase (Fig. A.11, row a)). Note that in the cases above the threshold $(0.40$ and $1.00 \mathrm{~A} \mathrm{~m}^{-2}$ ) $\left[\mathrm{S}_{8}\right]$ values start to level off as well, indicating that - as expected - $\left[\mathrm{S}_{8}\right]$ values are not the reason for the steep voltage increase in those cases.

Similarly, for the cases below the "infinite" charging threshold, $\left[\mathrm{S}^{2-}\right]$ values reach low plateau values after steep decreases, and a plateau-like gentle slope, inversely tracking the voltage evolution (Fig. A.11, row c)). For the same cases $\left[\mathrm{S}_{4}^{2-}\right]$ values (Fig. A.11, row b)) initially increase, reach a maximum at the end of the steep increase in voltage and $\left[S_{8}\right]$ values (at the start of the second charging voltage plateau), then decrease again and reach a plateau concurrently with 

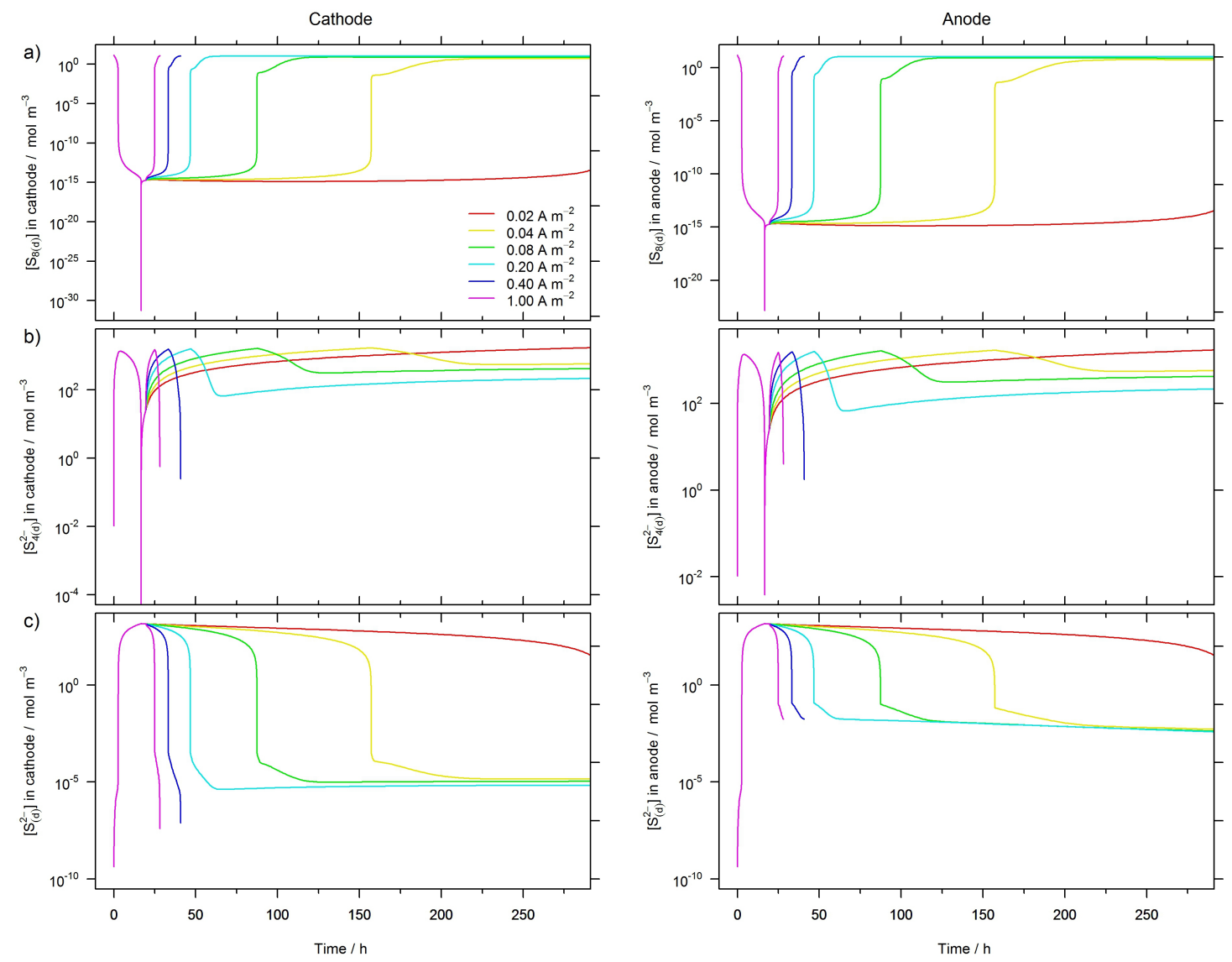

Figure A.11: Analysis of infinite-charging branch: concentrations of dissolved species on anode and cathode side. $\left(0.5 \mathrm{~A} \mathrm{~m}^{-2} \mathrm{CC}\right.$ discharge, followed by CC charges with the current densities given in the legend.) 
voltage and $\left[\mathrm{S}_{8}\right]$. However, for the cases above the "infinite" charging threshold, both $\left[\mathrm{S}^{2-}\right]$ and $\left[\mathrm{S}_{4}^{2-}\right]$ values decrease steeply, clearly indentifying their decrease as the cause for the steep voltage increase in those cases.

Qualitatively, dissolved species in cathode and anode show identical behavior: this is a result of comparatively high diffusion coefficients used in our model (left and right column, Fig. A.11).

As mentioned in the text, solid sulfur dissolution does not directly depend on charge current density, but on $\left[\mathrm{S}_{8}\right]$. After a discharge of the battery, the concentration of dissolved sulfur $\left[\mathrm{S}_{8}\right]$ is very low $\left(\approx 10^{-15} \mathrm{~mol} \mathrm{~m}^{-3}\right.$ after the deep discharge spike (Fig. A.11, row a)), orders of magnitude below the equilibrium value of $\left[\mathrm{S}_{8}\right]$ $\left(\approx 19 \mathrm{~mol} \mathrm{~m}^{-3}\right.$, same as in [31]). Ensuingly, the interplay between the redox reactions connecting the dissolved species (that do depend on current densities) first needs to lead to a significant rise in $\left[\mathrm{S}_{8}\right]$ (see steep increases in row a), Fig. A.11 ) before solid sulfur dissolution stops and eventually is reversed into precipitation (Fig. 6, panel b)).

\section{References}

[1] V. S. Kolosnitsyn, E. V. Karaseva, Lithium-sulfur batteries: Problems and solutions, Russian Journal of Electrochemistry 44 (5) (2008) Russian Acad Sci, Inst Organ Chem. doi: 10.1134/S1023193508050029.

[2] M. Barghamadi, a. Kapoor, C. Wen, A Review on Li-S Batteries as a High Efficiency Rechargeable Lithium Battery, Journal of the Electrochemical Society 160 (8) (2013) A1256-A1263. doi:10.1149/2.096308jes.

URL http://jes.ecsdl.org/cgi/doi/10.1149/2. 096308jes

[3] M.-K. Song, E. J. Cairns, Y. Zhang, Lithium/sulfur batteries with high specific energy: old challenges and new opportunities, Nanoscale 5 (2013) 2186-2204. doi:10.1039/C2NR33044J. URL http://dx.doi.org/10.1039/C2NR33044J

[4] S. S. Zhang, Liquid electrolyte lithium/sulfur battery: Fundamental chemistry, problems, and solutions, Journal of Power Sources 231 (2013) 153-162. doi:10.1016/j.jpowsour. 2012.12.102.

[5] S.-E. Cheon, K.-S. Ko, J.-H. Cho, S.-W. Kim, E.-Y. Chin, H.-T. Kim, Rechargeable Lithium Sulfur Battery II. Rate Capability and Cycle Characteristics, Journal of The Electrochemical Society 150 (6) (2003) A800-A805. doi : 10.1149/1.1571533. URL http://jes.ecsdl.org/cgi/doi/10.1149/1. 1571533

[6] P. G. Bruce, S. A. Freunberger, L. J. Hardwick, J.-M. Tarascon, Li-O2 and Li-S batteries with high energy storage., Nature Materials 11 (1) (2012) 19-29. doi:10.1038/nmat3191. URL http://www.ncbi.nlm.nih.gov/pubmed/22169914

[7] C. Barchasz, F. Molton, C. Duboc, J.-C. Lepretre, S. Patoux, F. Alloin, Lithium/Sulfur Cell Discharge Mechanism: An Original Approach for Intermediate Species Identification, Analytical Chemistry 84 (9) (2012) 3973-3980. doi:10.1021/ ac2032244.
[8] E. J. Cairns, H. Shimotake, High-temperature batt, Science 164 (3886) (1969) 1347-1355.

[9] H. Shimotake, M. Kyle, V. Maroni, E. Cairns, Lithium/sulfur cells and their potential for vehicle propulsion, Proc. of the First International Elec. Vehicle Symp., Nov. 5-7, 1969, Electric Vehicle Council, New York, NY.

[10] R. D. Rauh, F. S. Shuker, J. M. Marston, S. B. Brummer, Formation of Lithium Polysulfides In Aprotic Media, Journal of Inorganic \& Nuclear Chemistry 39 (10) (1977) 1761-1766. doi : 10.1016/0022-1902 (77)80198-X.

[11] R. D. Rauh, K. M. Abraham, G. F. Pearson, J. K. Surprenant, S. B. Brummer, A Lithium/Dissolved Sulfur Battery with an Organic Electrolyte, Journal of The Electrochemical Society 126 (4) (1979) 523-527. doi:10.1149/1.2129079.

[12] E. Peled, Y. Sternberg, A. Gorenshtein, Y. Lavi, Lithium-sulfur Battery - Evaluation of Dioxolane-based Electrolytes, Journal of the Electrochemical Society 136 (6) (1989) 1621-1625. doi: 10.1149/1.2096981.

[13] E. Peled, A. Gorenshtein, M. Segal, Y. Sternberg, Rechargeable Lithium Sulfur Battery, Journal of Power Sources 26 (3-4) (1989) 269-271. doi:10.1016/0378-7753(89)80133-8.

[14] H. S. Ryu, H. J. Ahn, K. W. Kim, J. H. Ahn, K. K. Cho, T. H. Nam, Self-discharge characteristics of lithium/sulfur batteries using TEGDME liquid electrolyte, Electrochimica Acta 52 (4) (2006) 1563-1566. doi:10.1016/j.electacta.2006.01. 086.

[15] J. Nelson, S. Misra, Y. Yang, A. Jackson, Y. Liu, H. Wang, H. Dai, J. C. Andrews, Y. Cui, M. F. Toney, In Operando X-ray diffraction and transmission X-ray microscopy of lithium sulfur batteries., Journal of the American Chemical Society 134 (14) (2012) 6337-43. doi:10.1021/ja2121926. URL http://www.ncbi.nlm.nih.gov/pubmed/22432568

[16] N. a. Cañas, K. Hirose, B. Pascucci, N. Wagner, K. A. Friedrich, R. Hiesgen, Investigations of lithium $₫$ sulfur batteries using electrochemical impedance spectroscopy, Electrochimica Acta 97 (2013) 42-51. doi:10.1016/j . electacta.2013.02.101.

[17] H.-J. Ahn, K.-W. Kim, A. Jou-Hyeon, G. Cheruvally, Lithium - Sulfur, in: J. Garche (Ed.), Encyclopedia of Electrochemical Power Sources, Secondary Batteries - Lithium Recharchable Systems, Elsevier, Amsterdam, 2009, pp. 155-161.

[18] B. Scrosati, J. Hassoun, Y.-K. Sun, Lithium-ion batteries. A look into the future, Energy \& Environmental Science 4 (9) (2011) 3287. doi:10.1039/c1ee01388b.

URL http: //xlink.rsc.org/?DOI=c1ee01388b

[19] B. Jin, J. U. Kim, H. B. Gu, Electrochemical properties of lithium-sulfur batteries, Journal of Power Sources 117 (1-2) (2003) 148-152. doi:10.1016/S0378-7753(03) 00113-7.

[20] H. S. Ryu, H. J. Ahn, K. W. Kim, J. H. Ahn, J. Y. Lee, Discharge process of $\mathrm{Li} / \mathrm{PVdF} / \mathrm{S}$ cells at room temperature, Journal of Power Sources 153 (2) (2006) Int Battery Assoc. doi : 10.1016/j.jpowsour. 2005.05.037.

[21] H.-S. Ryu, H.-J. Ahn, K.-W. Kim, J.-H. Ahn, K.-K. Cho, T.-H. Nam, J.-U. Kim, G.-B. Cho, Discharge behavior of lithium/sulfur cell with TEGDME based electrolyte at low temperature, Journal of Power Sources 163 (1) (2006) 201-206. doi:10.1016/j.jpowsour.2005.12.061.

[22] M. Nagao, Y. Imade, H. Narisawa, R. Watanabe, T. Yokoi, T. Tatsumi, R. Kanno, Reaction mechanism of all-solid-state lithium $\phi$ sulfur battery with two-dimensional mesoporous carbon electrodes, Journal of Power Sourcesdoi:10.1016/j. jpowsour.2013.05.037.

[23] D. Marmorstein, T. H. Yu, K. A. Striebel, F. R. McLarnon, J. Hou, E. J. Cairns, Electrochemical performance of lithium/sulfur cells with three different polymer electrolytes, Journal of Power Sources 89 (2) (2000) 219-226. doi:10. 
1016/S0378-7753(00)00432-8.

[24] S. E. Cheon, K. S. Ko, J. H. Cho, S. W. Kim, E. Y. Chin, H. T. Kim, Rechargeable lithium sulfur battery - I. Structural change of sulfur cathode during discharge and charge, Journal of the Electrochemical Society 150 (6) (2003) A796-A799. doi : 10.1149/1.1571532.

[25] B. H. Jeon, J. H. Yeon, I. J. Chung, Preparation and electrical properties of lithium-sulfur-composite polymer batteries Journal of Materials Processing Technology 143 (2003) 93-97. doi : 10.1016/S0924-0136(03) 00327-3.

[26] Y.-J. Choi, K.-W. Kim, H.-J. Ahn, J.-H. Ahn, Improvement of cycle property of sulfur electrode for lithium/sulfur battery, Journal of Alloys and Compounds 449 (1-2) (2008) 313-316. doi:10.1016/j.jallcom.2006.02.098.

[27] H. S. Ryu, Z. Guo, H. J. Ahn, G. B. Cho, H. Liu, Investigation of discharge reaction mechanism of lithium-liquid electrolyte - sulfur battery, Journal of Power Sources 189 (2) (2009) 1179-1183. doi:10.1016/j.jpowsour.2008.12.073.

[28] J. Hassoun, Y.-K. Sun, B. Scrosati, Rechargeable lithium sulfide electrode for a polymer tin/sulfur lithium-ion battery, Journal of Power Sources 196 (1) (2011) 343-348. doi:10.1016/j . jpowsour.2010.06.093.

[29] Y. Yang, G. Zheng, S. Misra, J. Nelson, M. F. Toney, Y. Cui, High-capacity micrometer-sized Li2S particles as cathode materials for advanced rechargeable lithium-ion batteries., Journal of the American Chemical Society 134 (37) (2012) 15387-94. doi:10.1021/ja3052206.

URL http://www.ncbi.nlm.nih.gov/pubmed/22909273

[30] Z. Wei Seh, W. Li, J. J. Cha, G. Zheng, Y. Yang, M. T. McDowell, P.-C. Hsu, Y. Cui, Sulphur-TiO2 yolk-shell nanoarchitecture with internal void space for long-cycle lithium-sulphur batteries., Nature communications 4 (2013) 1331. doi:10.1038/ ncomms 2327

[31] K. Kumaresan, Y. Mikhaylik, R. E. White, A Mathematica Model for a Lithium-Sulfur Cell, Journal of The Electrochemical Society 155 (8) (2008) A576-A582. doi:10.1149/1. 2937304.

[32] D. N. Fronczek, W. G. Bessler, Insight into lithium-sulfur batteries: Elementary kinetic modeling and impedance simulation, Journal of Power Sources 244 (2013) 183-188. doi: $10.1016 / j$.jpowsour. 2013.02.018.

[33] J. Shim, K. a. Striebel, E. J. Cairns, The Lithium/Sulfur Rechargeable Cell - Effects of electrode composition and solvent on cell performance, Journal of The Electrochemical Society 149 (10) (2002) A1321. doi:10.1149/1.1503076. URL http://jes.ecsdl.org/cgi/doi/10.1149/1. 1503076

[34] Y. V. Mikhaylik, J. R. Akridge, Low temperature performance of $\mathrm{Li} / \mathrm{S}$ batteries, Journal of the Electrochemical Society 150 (3) (2003) A306-A311. doi:10.1149/1.1545452.

[35] Y. Mikhaylik, J. Akridge, Polysulfide shuttle study in the Li/S battery system, Journal of The Electrochemical Society 151 (11) (2004) 1969-1976. doi:10.1149/1.1806394.

[36] W. G. Bessler, S. Gewies, M. Vogler, A new framework for physically based modeling of solid oxide fuel cells, Electrochimica Acta 53 (4) (2007) 1782-1800. doi:10.1016/j. electacta.2007.08.030

[37] J. P. Neidhardt, D. N. Fronczek, T. Jahnke, T. Danner, B. Horstmann, W. G. Bessler, A Flexible Framework for Modeling Multiple Solid, Liquid and Gaseous Phases in Batteries and Fuel Cells, Journal of the Electrochemical Society 159 (9) (2012) A1528-A1542. doi:10.1149/2.023209jes.

[38] V. Yurkiv, D. Starukhin, H.-R. Volpp, W. G. Bessler, Elementary Reaction Kinetics of the $\mathrm{CO} / \mathrm{CO}_{2} / \mathrm{Ni} / \mathrm{YSZ}$ Electrode, Journal of The Electrochemical Society 158 (1) (2011) B5. doi:
$10.1149 / 1.3505296$

[39] V. Yurkiv, A. Utz, A. Weber, E. Ivers-Tiffée, H.-R. Volpp, W. G. Bessler, Elementary kinetic modeling and experimental validation of electrochemical $\mathrm{CO}$ oxidation on Ni/YSZ pattern anodes, Electrochimica Acta 59 (2012) 573-580. doi : 10.1016/ j.electacta.2011.11.020.

[40] C. Hellwig, S. Sörgel, W. Bessler, A Multi-Scale Electrochemical and Thermal Model of a LiFePO4 Battery, ECS Transactions 35 (32) (2011) 215-228.

URL http://ecst.ecsdl.org/content/35/32/215. short

[41] B. Horstmann, T. Danner, W. G. Bessler, Precipitation in aqueous lithium-oxygen batteries: a model-based analysis, Energy \& Environmental Science 6 (4) (2013) 1299-1314. doi:10. 1039/c3ee24299d.

URL http: //xlink.rsc.org/?DOI=c3ee24299d

[42] M. H. Ryou, D. J. Lee, M. Y. Lee, J. K. Park, J. W. Choi, Excellent Cycle Life of Lithium-Metal Anodes in Lithium-Ion Batteries with Mussel-Inspired Polydopamine-Coated Separators, Adv. Energy Mater. 2 (2012) 645-650.

[43] R. Bhattacharyya, B. Key, H. Chen, A. S. Best, A. F. Hollenkamp, C. P. Grey, In situ NMR observation of the formation of metallic lithium microstructures in lithium batteries., Nature materials 9 (6) (2010) 504-10. doi:10.1038/nmat2764. URL http://www.ncbi.nlm.nih.gov/pubmed/20473288

[44] R. S. Thompson, D. J. Schroeder, C. M. López, S. Neuhold, J. T. Vaughey, Stabilization of lithium metal anodes using silanebased coatings, Electrochemistry Communications 13 (12) (2011) 1369-1372. doi:10.1016/j .elecom.2011.08.012.

[45] S. F. Sciamanna, S. Lynn, Sulfur solubility in pure and mixed organic solvents, Industrial \& Engineering Chemistry Research 27 (3) (1988) 485-491. doi:10.1021/ie00075a019.

[46] D. G. Goodwin, et al., Cantera (2001-2010). URL http: //code.google.com/p/cantera

[47] A. F. Holleman, E. Wiberg, Lehrbuch der Anorganischen Chemie, 33rd Edition, Walter de Gruyter, Berlin, New York, 1985.

[48] P. W. Atkins, Physikalische Chemie, 2nd Edition, VCH, Weinheim, 1996.

[49] D. R. Lide, CRC Handbook of Chemistry and Physics, 87th Edition, CRC Press, 2006

[50] MSDS (Santa Cruz Biotechnology Inc.), Tetraglyme: sc213018, Tech. rep., Santa Cruz Biotechnology, Inc. (2010). URL http: //datasheets.scbt.com/sc-213018.pdf

[51] H. Tokuda, K. Hayamizu, K. Ishii, M. A. B. H. Susan, M. Watanabe, Physicochemical Properties and Structures of Room Temperature Ionic Liquids. 1. Variation of Anionic Species, The Journal of Physical Chemistry B 108 (42) (2004) 16593-16600. doi:10.1021/jp047480r.

URL http://pubs.acs.org/doi/abs/10.1021/ jp047480r

[52] C. Capiglia, Y. Saito, H. Kageyama, P. Mustarelli, T. Iwamoto, T. Tabuchi, H. Tukamoto, $7 \mathrm{Li}$ and $19 \mathrm{~F}$ diffusion coefficients and thermal properties of non-aqueous electrolyte solutions for rechargeable lithium batteries, Journal of Power Sources 81-82 (1999) 859-862.

[53] Celgard, Celgard (R) 3501 by Celgard LLC (2012). URL http://www.environmental-expert.com/ products/\$ \mskip\thickmuskip\$celgard-3501-65760/ view-comments

[54] J. Choi, J. Kim, G. Cheruvally, J. Ahn, H. Ahn, K. Kim, Rechargeable lithium/sulfur battery with suitable mixed liquid electrolytes, Electrochimica Acta 52 (5) (2007) 2075-2082. doi:10.1016/j.electacta.2006.08.016.

[55] Y. Diao, K. Xie, S. Xiong, X. Hong, Insights into Li-S Battery 
Cathode Capacity Fading Mechanisms: Irreversible Oxidation of Active Mass during Cycling, Journal of The Electrochemical Society 159 (11) (2012) A1816-A1821. doi:10.1149/2. 020211jes.

[56] C. Wang, J.-j. Chen, Y.-n. Shi, M.-s. Zheng, Q.-f. Dong, Preparation and performance of a corecshell carbon/sulfur material for lithium/sulfur battery, Electrochimica Acta 55 (23) (2010) 7010-7015. doi:10.1016/j.electacta.2010.06.019.

[57] B. Zhang, X. Qin, G. R. Li, X. P. Gao, Enhancement of long stability of sulfur cathode by encapsulating sulfur into micropores of carbon spheres, Energy \& Environmental Science 3 (10) (2010) 1531. doi:10.1039/c002639e.

URL http: //xlink.rsc.org/?DOI=c002639e

[58] F. Wu, J. Chen, R. Chen, S. Wu, L. Li, S. Chen, T. Zhao, Sulfur/Polythiophene with a Core/Shell Structure: Synthesis and Electrochemical Properties of the Cathode for Rechargeable Lithium Batteries, The Journal of Physical Chemistry C 115 (13) (2011) 6057-6063. doi:10.1021/jp1114724.

URL http://pubs.acs.org/doi/abs/10.1021/ jp1114724

[59] J. Kim, D.-J. Lee, H.-G. Jung, Y.-K. Sun, J. Hassoun, B. Scrosati, An Advanced Lithium-Sulfur Battery, Advanced Functional Materials 23 (8) (2013) 1076-1080. doi : 10.1002/ adfm. 201200689.

[60] J.-H. J. Yu, J. J.-W. Park, Q. Wang, H.-S. H. Ryu, K.-W. Kim, J.-H. Ahn, Y. Kang, G. Wang, H.-J. Ahn, Electrochemical properties of all solid state Li/S battery, Materials Research Bulletin (2012) 10-12doi:10.1016/j.materresbull.2012. 04.086.

[61] B. Horstmann, B. Gallant, R. Mitchell, W. G. Bessler, Y. ShaoHorn, M. Z. Bazant, Rate-dependent morphology of $\mathrm{Li}_{2} \mathrm{O}_{2}$ growth in $\mathrm{Li}-\mathrm{O}_{2}$ batteries, J. Phys. Chem. Lett. 4 (2013) 4217 4222 . 